\title{
Integritas Diri Tokoh Utama Pada Film "The Ron Clark Story" Karya Randa Haines
}

\author{
Tuti Apriani ${ }^{\mathrm{a}, 1}$, Zainal Rafli ${ }^{\mathrm{a}, 2}$, dan Zuriyati ${ }^{\mathrm{a}, 3}$ \\ ${ }^{a}$ Universitas Negeri Jakarta, Indonesia \\ 'tutiapriani@mahasiswa.unj.ac.id, ${ }^{2}$ zainal.rafli@unj.ac.id, ${ }^{3}$ zuriyati_adab@yahoo.com
}

\begin{tabular}{ll}
\hline Article info & A B S T R A C T \\
\hline Article history: & This research examines and analyzes the integrity of the main \\
Revised :06-10-2019 & characters in the film The Ron Clark Story by Randa Haines \\
Accepted:06-11-2019 & through the depiction of the basic dimensions of man. The film \\
& Ron Clark Story tells of a teacher named Ron Clark, he is a \\
& teacher who excels. However, because he wanted to have new \\
& experiences he moved to the big city of New York. Clark is a \\
figure who has self-integrity, despite many obstacles and & obstacles in realizing self-integrity. The self-integrity of Ron \\
& Clark's character is examined through the depiction of basic \\
& human dimensions which consist of: physical dimensions, \\
& psychological dimensions, and social dimensions.
\end{tabular}

Keywords:

dimensions

integrity

physical

psychological

social
Penelitian ini bertujuan untuk mengkaji dan menganalisis integritas diri tokoh utama pada film The Ron Clark Story Karya Randa Haines melalui penggambaran dimensi dasar manusia. Film The Ron Clark Story menceritakan tentang seorang guru bernama Ron Clark, dia merupakan guru yang berprestasi. Akan tetapi, karena ingin mempunyai pengalaman baru dia pindah ke kota besar New York. Clark merupakan tokoh yang mempunyai integritas diri, walaupun banyak halangan dan hambatan dalam mewujudkan integritas diri. Integritas diri tokoh Ron Clark dikaji melalui penggambaran dimensi dasar manusia yang terdiri atas: dimensi fisik, dimensi psikis, dan dimensi sosial.

Copyright $(\odot 2019$ Institut Agama Islam Negeri Syekh Nurjati Cirebon. All rights reserved.

\section{PENDAHULUAN}

Karya sastra menjadi sarana untuk menyampaikan pesan tentang kebenaran.

Karya sastra pada hakikatnya merupakan penjelmaan angan serta pengalaman pengarang dengan mengandalkan imajinasinya sebagai suatu hal yang akan menjadi dasar kekuatan pada karya sastra tersebut. Film dalam studi sastra mempunyai hubungan satu sama lain, Film merupakan media penyampai pesan dan alat komunikasi massa (Syaukat \& Imanjaya, 2011). Karya seni kontemporer dalam bentuk film adalah sastra yang sangat modern dan sangat erat kaitannya dengan siswa dari kelas satu tingkat pendidikan dan menjadi tugas kerja sastra bagi siswa di perguruan tinggi (Ceretti, 2015).

Pendidikan formal atau sekolah, mempunyai peranan yang amat 
menentukan perkembangan potensi manusia secara maksimal, sehingga manusia itu memiliki ketajaman respon terhadap lingkungannya, keterampilan, intelektual, sehat dan berkehidupan yang baik, koperatif, mempunyai motivasi yang tinggi untuk berprestasi, mampu berkompetisi, toleran, dapat menghargai pendapat orang lain, dan mampu mencapai kebahagiaan hidup (Setiawan, 2011). Tanis (2013) mengatakan bahwa pendidikan merupakan suatu perbuatan atau tindakan sadar agar terjadi perubahan sikap dan tata laku yang diharapkan yaitu pemanusian manusia yang cerdas, terampil, mandiri, berdisiplin, dan berakhlak mulia.

Cohen (2014) mengatakan bahwa setiap orang memiliki kebutuhan dasar untuk menjaga integritas diri, rasa global dan kecukupan pribadi. Oleh karena itu integritas diri merupakan hal penting yang harus dimiliki setiap orang. Umumnya kata integritas lebih banyak dikaitkan dengan kepemimpinan dalam berbagai bidang: kepemimpinan dalam dunia bisnis, lingkup pemerintahan, lingkup organisasi, dan kemasyarakatan. Itu tidak berarti bahwa yang dituntut memiliki integritas itu hanyalah mereka yang menjadi pemimpin. Semua orang, khususnya orang-orang dewasa, teristimewa yang berpendidikan diharapkan memiliki integritas (Gea, 2014).

Montifiore dan Vines (1999) mengatakan bahwa integritas adalah terletak pada titik untuk berupaya menghadapi segala godaan walaupun dalam keadaan yang menyakitkan. Sedangkan, Cottingham (dalam Archer, 2017) mengatakan bahwa integritas adalah hubungan formal koherensi antara berbagai aspek seseorang. Barnard, Schurink, dan De Beer, (2008) mengatakan bahwa integritas merupakan konstruksi psikologis yang berdampak pada perilaku di tempat kerja, menerima banyak perhatian dalam berbagai domain psikologi industri dan organisasi, seperti kepemimpinan, dinamika organisasi, kesehatan karyawan, dan pemilihan karyawan. Parker (2013) mengatakan bahwa kemampuan seseorang untuk menerima masa lalu dan berkontribusi terhadap sikap yang berhubungan dengan ego integritas. Menurut Dunn (2009) integritas adalah konsistensi sesuai konteks, koherensi antara nilai-nilai dan tindakan, stabilitas dari waktu ke waktu, permanen di seluruh peran, dan persatuan perspektif etis.

Gea (2005) mengatakan bahwa Integritas diri yaitu tidak lain adalah suatu pemahaman dimana terwujudnya perkembangan yang seimbang dan sinergis atas 
semua dimensi diri manusia secara berkelanjutan. mengatakan dimensi-dimensi dasar diri manusia manusia adalah sebagai berikut: 1)Dimensi badan/fisik yaitu yang berkaitan dengan hal-hal yang bersifat material, dengan kebutuhan utama: makan, sandang, dan papan (perumahan). 2) Dimensi jiwa/psikis merupakan dimensi dasar kedua dari manusia, yang hakekatnya adalah aspek kejiwaan, yang meliputi pemikiran, inteligensi, hal-hal yang berkaitan dengan emosi, unsur-unsur kerohanian, atau hal-hal yang mencakup untuk unsur batiniah lainnya. 3) Dimensi Sosial yaitu dipahami dan diakui sebagai salah satu dimensi dasariah kehidupan manusia di dunia ini. Kebutuhan-kebutuhan yang berkaitan dengan dimensi sosial manusia meliputi terutama: kebutuhan akan penerimaan dan mencintai, pengakuan dan persahabatan serta segala bentuk hubungan sosial lainnya ( Gea et al., 2005).

Salah satu film yang diangkat dari suatu kisah nyata yaitu film The Ron Clark Story. Film ini menggambarkan tentang integritas diri pada tokoh utama yaitu Clark. Film hasil produksi Turner Network Television (TNT) Amerika ini yang disutradarai oleh Randa Haines yang diliris pada tahun 2006 dan masuk dalam daftar 28 film pendidikan terbaik di dunia yang memberikan inspirasi dalam dunia pendidikan. The Ron Clark Story adalah film yang bersumber dari sebuah kisah nyata yang kemudian diadaptasi menjadi film. Film The Ron Clark Story mengangkat cerita tentang seorang guru yang bernama Clark, dia merupakan seorang guru yang cerdas, pekerja keras dan pantang menyerah. Clark semula menjadi guru di Snowden Elementary school di Aurora, North California pada tahun 1994.Clark adalah seorang pendidik yang mempunyai komitmen, konsisten, dan bertanggung jawab terhadap pekerjaannya. Clark mempunyai integritas diri yang tinggi. Clark dapat menghadapi segala hambatan dan tantangan yang dihadapinya.

\section{METODE}

Penelitian ini menggunakan metode kualitatif dengan teknik analisis isi(content analysis). Penelitian kualitatif mengandung pendekatan naturalistik dan interpretive (Denzin \& Lincoln, 2000). Analisis isi yang sifatnya kualitatif tidak hanya mampu mengidentifikasi pesan-pesan manifest, melainkan juga latent messages dari sebuah dokumen yang diteliti (Sartika, 2014). Data dalam 
penelitian ini adalah berupa kata-kata, kalimat, dialog, dan cuplikan gambar yang terdapat dalam film The Ron Clark Story yang telah diiventarisasikan serta diklasifikasi sesuai dengan format pencatatan, selanjutnya dianalisis berdasarkan integritas diri melalui penggambaran dimensi dasar manusia yang telah dipaparkan dalam uraian diatas. Tahap analisis dilakukan dalam penelitian ini dengan cara sebagai berikut: 1) mendeskripsikan data yang berhubungan dengan dimensi dasar manusia, 2) mengidentifikasi data sesuai dengan dimensi dasar manusia, 3) Mengiventasikan data, 4) membuat kesimpulan berdasarkan hasil penelitian, 5) melaporkan hasil penelitian. Teknik pengabsahan data yang digunakan adalah teknik uraian rinci.

\section{HASIL DAN PEMBAHASAN}

Integritas diri pada tokoh utama dalam film The Ron Clark Story karya Randa Haines melalui penggambaran dimensi dasar manusia yang terdiri dari: dimensi fisik, dimensi psikis, dan dimensi sosial. Dalam film The Ron Clark Story karya Randa Haines, difokuskan pada integritas diri tokoh utama yakni terdapat dalam dimensi dasar manusia yang terdiri dari: dimesi fisik, dimensi psikologis, dan dimensi sosial. Dimensi psikologis yaitu terdapat 3 unsur kecerdasan yang tak bisa dipisahkan yaitu: kecerdasan intelektual, kecerdasan emosional, dan kecerdasan spiritual.

\section{Dimensi Fisik}

Dari keseluruhan aspek (sebagai dimensi) yang membentuk diri manusia, aspek inilah yang merupakan unsur paling riil dimata kita (Gea et al., 2005). Dimensi fisik dalam film The Ron Clark Story karya Randa Haines yaitu hal-hal yang bersifat material, seperti kebutuhan utama: makan, sandang, dan papan (perumahan). Clark mencari penginapan sesampainya di Harlem New York.

Setting: Dilobi penginapan.

Tokoh: Ron Clark dan Yolanda.

Adegan dimulai pada menit 04.46

Yolanda : Rent's due at 10:00, cash only and checkout's at 11:30.

Ron Clark : Okay, This is great. And, what's your name?

Yolanda : Yolanda

Ron Clark : Thank you Yolanda. 
Clark nampak kewalahan menghadapi murid-muridnya pada saat pertama mengajar di Inner Harlemn Elementary School. Kelas yang berantakan dan tidak ada satupun murid yang mendengar dan menyimak yang dia ajarkan dikelas. Clark kelelahan menyiapkan materi bahan ajar untuk dia gunakan mengajar diesok hari. Clark selalu menyiapkan media dan bahan ajar dengan baik supaya murid-muridnya dapat memahami apa yang dia ajarkan dengan baik. Walaupun dalam keadaan sakit Clark tetap mengoreksi hasil ulangan harian murid-muridnya. Dan, dia menyiapkan bahan ajar dengan baik. Karena ujian nasional yang semakin dekat. Clark berkomitmen dia akan mengajar dengan baik dan membuat semua muridnya lulus dalam ujian nasional.

Clark berobat ke klinik memeriksakan kesehatannya. Dokter menyarankan Clark untuk beristirahat dirumah minimal selama 2 minggu. Sedangkan, ujian nasional sebentar lagi. Clark khawatir murid-muridnya akan tidak bisa mengikuti ujian nasional dengan baik apabila dia harus beristirahat dan tidak mengajar.

\section{Dimensi Psikologis}

Dimensi psikologis memperlihatkan kekhasan setiap pribadi individu dan sangat menentukan bagi kelangsungan perkembangan dan perjalanan hidup manusia(Gea et al., 2005). Dimensi psikis dalam film The Ron Clark Story karya Randa Haines yaitu terdiri dari: kecerdasan intelektual, kecerdasan emosional, dan kecerdasan spiritual yang dimiliki oleh tokoh utama yaitu Ron Clark.

\section{Kecerdasan intelektual}

Kecerdasan intelektual dikaitkan dengan kecerdasan otak, pemikiran rasional dan logis serta dihubungkan sangat ketat dengan pemeringkatan akademis (Gea et al., 2005). Clark merupakan tokoh utama yang mempunyai kecerdasan intelektual tinggi. Clark menemukan seorang murid yang harus berdiri ditong sampah karena dihukum oleh gurunya. Kemudian, Clark menghampiri anak tersebut untuk berkenalan. Clark berpendapat bahwa belajar tidak hanya bisa dilakukan didalam kelas. Kapanpun dan dimanapun berada bisa belajar. 
Setting: Didepan ruang kelas di Snowden Elementary School.

Tokoh: Ron Clark dan Hadley Craigh.

Adegan dimulai pada menit 00.44

Ron Clark : Hai, what happened to you?

Hadley Craigh: Teacher says I can't learn. So I should go out with the trash.

Ron Clark : Okay, settle down. Let's get out our silent reading. I am mr. clark. What your name?

Hadley Craigh: Hadley Craigh

Ron Clark : Nice to meet you. Uh you know . I'm so sorry. I'm forgetful . what's my name again?

Hadley Craigh: It's Mr. Clark

Ron Clark : oh see? You just learned something. Let's get you out of there.

Clark melamar untuk menjadi guru di sekolah-sekolah sekitar Harlem New York. Namun, dia mendapatkan berbagai penolakan, Clark berusaha menyakinkan kepala sekolah di Harlem bahwa dia mempunyai kemampuan untuk meningkatkan nilai murid-muridnya pada ujian nasional.Clark membuat kesepakatan dengan murid-muridnya. Dia akan meminum semua susu coklat yang ada dimeja setiap 15 detik sekali, dengan kesepakatan murid-muridnya harus diam, mendengarkan, dan menyimak apa yang dia ajarkan dikelas. Clark mengajarkan nama-nama Presiden di Amerika dengan bergaya seperti penyayi Rap. Clark yakin dengan metode yang dia gunakan akan lebih mudah diterima dan dipahami oleh murid-muridnya. Dan, murid-muridnya pun mudah dalam menghapal nama-nama presiden yang ada di Amerika.

\section{Kecerdasan emosional}

Clark berpamitan kepada orangtuanya untuk pindah ke New York. Dia sangat menyukai tinggal di North California, dan diapun sangat berat untuk berjauhan dengan kedua orangtuanya. Namun, disisi lain Clark harus tetap pindah ke New York. Clark meyakinkan ayahnya bahwa keputusannya untuk pindah ke kota New York merupakan jalan yang terbaik untuk mewujudkan mimpinya. Clark juga ingin membuktikan apa yang telah dia ucapkan kepada muridmuridnya bahwa untuk mewujudkan mimpi besar harus berani mengambil risiko termasuk dengan berpindah kota.

Setting: Meyakinkan Ayahnya tentang keputusannya untuk pindah.

Tokoh : Ron Clark. Adegan dimulai pada menit 03.13

Ron : Dad, every year I tell my students to go for what they want in life. Dream big, take risk. It's time I started living up to my own words. 
Clark pergi keluar kelas karena marah terhadap muridnya yang tidak mendengarkannya dikelas. Dia mulai menyerah menghadapi tingkah muridnya tersebut. Clark mengajak Marissa untuk keliling kota New York. Dia ingin meceritakan semua permasalahan yang dihadapinya disekolah. Clark membutuhkan teman untuk bertukar pikiran. Clark mencurahkan tentang masalahnya disekolah. Clark mulai merasa putus asa menghadapi tingkah laku murid-muridnya disekolah. Clark merasa dia tidak cukup mampu mengatasi murid-muridnya yang susah diatur dan tidak menganggap keberadaannya dikelas. Namun, Marissa memberikan Clark semangat untuk kembali ke sekolah, karena murid-muridnya sangat membutuhkan Clark.

Setting: Clark bertukar pikiran dengan Marissa.

Tokoh: Ron Clark dan Marissa Vega. Adegan dimulai pada menit 36.41

Ron Clark : Today, I'm gave up.

Marrisa Vega : Don't give up Ron.

Ron Clark : Oh, yeah. How long has it been since you've auditioned?

Marissa Vega : I don't know. 2 years and 7 months.

Mr. Turner meragukan kemampuan Clark dalam mengajar para siswanya. Sedangkan, ujian nasional semakin dekat waktunya. Akan tetapi Clark menyakinkan Mr. Turner bahwa semua siswanya akan lulus dalam ujian nasional tersebut. Clark kecewa nilai ulangan harian murid-muridnya menurun, karena Clark sakit sehingga harus istirahat dirumah. Clark meyakinkan murid-muridnya bahwa mereka telah berjuang dan belajar supaya bisa lulus ujian nasional. Hal tersebut ditunjukan pada kutipan di bawah ini:

Setting: Clark kecewa dengan hasil ulangan murid-muridnya.

Tokoh: Ron Clark. Adegan dimulai pada menit 01.07.36

Ron Clark : We're not behind. You're a head! Every day in this room we are learning things far more valuable than you can get in some book. I teach you and you teach me. And, together, we learn to love to learn.

Di saat para siswanya mulai menyerah dan kehilangan semangat dalam menghadapi ujian nasional, Clark berusaha menyakinkan dan memberikan semangat kepada para siswanya. Selama ini Clark dan para siswanya sudah banyak belajar dan berjuang untuk mempersiapkan ujian nasional. Sehingga, tidak ada alasan untuk mereka merasa tidak percaya diri dengan kemampuan dan usaha yang telah dilakukan selama ini. Clark menunggu murid-muridnya yang sedang 
ujian nasional di depan ruang ujian bersama guru lainnya. Clark merasa gugup dan khawatir murid-muridnya tidak bisa mengerjakan soal ujian nasional. Namun, dia berusaha agar tidak terlihat seperti orang yang gugup.

Setting: Disaat menunggu para murid yang sedang ujian nasional.

Tokoh: Ron Clark dan Guru 1. Adegan dimulai pada menit 01.12.55

Teacher 1 : Think they're a nervous as we are?

Ron Clark : I'm not nervous.

Clark berusaha tidak menunjukan kegugupannya di depan guru lain saat menunggu para siswanya yang sedang menghadapi ujian nasional. Walaupun, sebenarnya dia sangat gugup dan khawatir dengan berlangsungnya ujian nasional. Namun, dia berusaha untuk mengendalikan emosinya agar terlihat tetap tenang.

Clark memberikan kejutan untuk murid-muridnya yang telah belajar dengan baik untuk ujian nasional. Clark memberikan tiket nonton opera untuk muridmurid dan orang tuanya. Clark memberikan apresiasi kepada murid-muridnya, karena telah bekerja keras belajar untuk ujian nasional. Hal tersebut ditunjukan pada kutipan dibawah ini:

Setting: Monolog Clark dikelas.

Tokoh: Clark.

Adegan dimulai pada menit 01.15.25

Ron Clark : You guys have been working so hard for the last months on this test, and whatever the score are, I want you to know I'm proud to be your teacher. I'm so proud that I asked your parents to let me take you somewhere special, and they said yes. So, go get your envelopes and open them.

Setelah ujian nasional berlangsung, Clark memberikan kejutan untuk para siswa dan orangtua. Clark mengajak para siswa dan orangtua pergi menonton opera, hal tersebut sebagai apresiasi atas usaha yang telah dilakukan para siswa dalam menghadapi ujian nasional. Mr. Turner datang untuk memberitahukan Clark bahwa murid-muridnya lulus dalam ujian nasional. Dan, murid-muridnya mendapatkan nilai terbaik diantara sekolah lainnya. Hal tersebut ditunjukan pada kutipan di bawah ini. 
Setting: Hasil ujian nasional.

Tokoh: Ron Clark dan Mr. Turner.

Adegan dimulai pada menit 01.22.09

Mr. Turner : I'm sorry to interupt. Your end of the year party, Mr. Clark. But, I just received a fax from the board of education, informing me of the results of the state exam. I felt it was important to give you the scores my self. These are probably not the score you excepted. This class, this sixth grade class tested higher than any other class. You even tested higher than the honors class. Congratulations. Congratulations Mr. Clark.

Ron Clark : Thank you.

Principal Turner: Very impressive.

Pada saat acara perpisahan kelas berlangsung, Mr. Turner datang menghampiri Clark dengan membawa kabar berita tentang hasil ujian nasional. Para siswa yang Clark ajar semuanya lulus dalam ujian tersebut serta mendapatkan nilai terbaik diantara kelas lainnnya di Harlem. Pencapaian tersebut merupakan suatu hal yang sangat membanggakan bagi Clark dan para siswanya. Clark membuat perayaan perpisahan sekolah untuk murid-muridnya. Dia memberikan piala untuk murid-murid yang berprestasi dalam bidangnya masingmasing. Tak disangka, Clark mendapatkan berita dari Mr. Turner bahwa muridmuridnya lulus ujian nasional dan mendapatkan nilai terbaik di antara sekolah lainnya.

Clak tampak berpelukan dengan para siswanya, mereka merayakan keberhasilan lulus dalam ujian nasional dengan nilai terbaik di Harlem. Clark sangat bahagia dan bangga atas prestasi yang telah dicapai oleh muridnya. Semua jerih payah dan usahanya untuk mengajar muridnya walaupun banyak halangan dan rintangan yang dihadapi, karena Clark mempunyai integritas diri maka hal tersebut dapat dilaluinya.

\section{Kecerdasan spiritual}

Clark mengejar Tayshwan yang keluar kelas setelah berkelahi dengan Julio. Clark meyakinkan bahwa Tayshawn mempunyai kepribadian yang baik. Dan, dia meminta Tayshawn untuk kembali ke kelas. Karena Clark percaya bahwa setiap anak adalah anak yang baik. 
Setting: Tangga sekolah.

Tokoh Ron Clark dan Tayshawn.

Adegan dimulai pada menit 32.19

Ron Clark : Look, don't do this! Hey! Look, I knew you have 2 strikes. You walk out now, they'll expel you for sure. Just get back in here.

Tayshwan : Why?

Ron Clark : Because, I would your glowing personality. Mr. Turner doesn't have to know anything about this. Just give yourself another chance.

Clark memberikan kejutan untuk murid-muridnya yang telah belajar dengan baik untuk ujian nasional. Clark memberikan tiket nonton opera untuk muridmurid dan orang tuanya. Clark memberikan apresiasi kepada murid-muridnya, karena telah bekerja keras belajar untuk ujian nasional. Hal tersebut ditunjukan pada kutipan di bawah ini.

Setting: Monolog Clark di kelas.

Tokoh: Clark.

Adegan dimulai pada menit 01.15.25

Ron Clark : You guys have been working so hard for the last months on this test, and whatever the score are, I want you to know I'm proud to be your teacher. I'm so proud that I asked your parents to let me take you somewhere special, and they said yes. So, go get your envelopes and open them.

\section{Dimensi Sosial}

Dimensi sosial adalah kebutuhan-kebutuhan yang berkaitan dengan dimensi sosial manusia meliputi: kebutuhan akan penerimaan dan mencintai, pengakuan dan persahabatan serta segala bentuk hubungan sosial lainnya (Gea et al., 2005). Dimensi sosial dalam film The Ron Clark Story yaitu sikap tolong menolong dan saling menyayangi. Clark meminta daftar sekolah yang ada di Harlem New York. Dia ingin melamar untuk mengajar disekolah disekitar Harlem. Namun, Yolanda resepsionis tempat Clark menginap, mengingatkan Clark untuk berhati-hati ketika mengajar didaerah Harlem, karena siswa di sana terkenal suka bertengkar bahkan sering menganiaya guru. 
Setting: Clark meminta daftar sekolah yang ada di Harlem kepada Yolanda.

Tokoh: Ron Clark dan Yolanda.

Adegan dimulai pada menit 05.41

Ron Clark : Yolanda, good morning. Do you have a list of the public schools in Harlem?

Yolanda : Sure I do, baby.

Ron Clark : Okay, thank you.

Yolanda : What do you want school listings for?

Ron Clark : I'm a teacher.

Yolanda : And you wanna teach - up in Harlem?

Ron Clark : Yes.

Yolanda : Well then, honey, you're gonna need something else. Personal injury lawyers. Cause once your white behind goes on up in there they be carrying you back up the same way you went in. What kind of foolishness is this? Going on up there and all trying to teach? You know you ain't gonna...

Ron Clark : Okay thank you.

Yolanda berusaha memberitahukan Clark untuk memikirkan kembali keputusannya dengan melamar kerja di sekolah sekitar Harlem. Para siswa sekitar Harlem dikenal suka susah diatur, sering bertengkar dikelas, bahkan menganiaya gurunya. Sebelum mulai mengajar, Clark mengunjungi rumah salah satu muridnya yang bernama Badriyah yang berasal dari India. Clark ingin berkenalan dan mengetahui latar belakang keluarga murid-muridnya sebelum dia mengajar. Sebelum mulai mengajar disekolah Inner Harlem Elementary School, Clark mengunjungi rumah para siswanya. Dengan tujuan untuk berkenalan dan mengetahui tentang latar belakang keluarga para siswanya tersebut. Clark mengatakan kepada murid-muridnya bahwa mulai sekarang mereka harus menganggap bahwa hubungan antara guru dengan murid adalah seperti sebuah keluarga. Keluarga yang akan saling menghargai dan menghormati.

Setting: Monolog Clark didalam kelas.

Tokoh: Ron Clark.

Adegan dimulai pada menit 17.25

Ron Clark : This year is going to be about more than school. This year, we are going to be a family.

Clark mengatakan bahwa hubungan dia dengan para siswanya sama seperti sebuah keluarga. Sehingga, harus saling menghargai, menyayangi, dan tidak berbohong satu sama lainnya. Clark mengejar Tayshwan yang keluar kelas setelah 
berkelahi dengan Julio. Dia meyakinkan bahwa Tayshawn mempunyai kepribadian yang baik, dan meminta Tayshawn untuk kembali ke kelas.

Setting: Clark membujuk Tayshawn.

Tokoh: Ron Clark dan Tayshawn.

Adegan dimulai pada menit 32.19

Ron Clark : Look, don't do this! Hey! Look, I knew you have 2 strikes. You walk out now, they'll expel you for sure. Just get back in here

Tayshwan : Why?

Ron Clark : Because, I would your glowing personality. Mr. Turner doesn't have to know anything about this. Just give yourself another chance.

Clark bermain double ducth atau lompat tali bersama murid-muridnya dihalaman sekolah. Dia membuat kesepakatan dengan Shameika mengajarinya belajar lompat tali. Kemudian, Clark akan mengajar dan menjawab apapun yang ingin diketahui oleh Shameika. Clark sangat peduli terhadap murid-muridnya. Dia berusaha agar para muridnya bisa belajar dengan baik. Clark mengantarkan hasil ulangan harian Tayshawn. Karena, Tayshawn tidak masuk sekolah. Tetapi, Clark selalu memberikan motivasi bahwa Tayshawn bisa lulus dalam ujian nasional yang akan dihadapinya.

Clark meyakinkan Ms. Wallace bahwa anaknya Shameika merupakan anak yang cerdas dan mempunyai kemampuan untuk menjadi pemimpin. Clark yakin apabila Shameika diberikan waktu untuk belajar, maka Shameika bisa masuk sekolah menengah pertama terbaik di Mahattan.

Setting: Clark meyakinkan Ms. Wallace tentang Shameika.

Tokoh: Ron Clark dan Ms. Wallace.

Adegan dimulai pada menit 57.06

Ron Clark : Ms. Wallace wait.

Ms. Wallace : I'l meet you outside (said to Shameika). Why are you doing this? You gave her these grand ideas, and this world is just going to crush her down.

Ron Clark : I don't believe that.

Ms. Wallace : So, you're just going to drop into her life. And now, you know all about it, right?

Ron Clark : I just know she's a great student. A born leader, creative, intelligent.

Ms. Wallace : Shameika? My Shameika?

Ron Clark : Yes. If she test well enough in May, I think we might be able to get her into Manhattan West for middle school.

Ms. Wallace : That's for gifted kids. Maybe Mrs. Benton Can keep the boys a little longer every day.

Ron Clark : Ok..

Ms. Wallace : Ok.. 


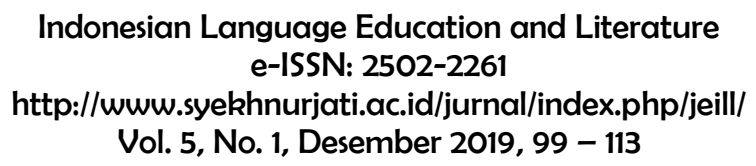

Clark meminta Ms. Wallace untuk memberikan waktu lebih untuk Shameika agar dapat belajar. Karena, selama ini Shameika harus mengurus ketiga adiknya yang masih kecil selama ibunya bekerja. Sehingga, dia tidak mempunyai waktu untuk belajar. Sedangkan, Shameika merupakan siswa yang cerdas dan mempunyai kemampuan lebih. Clark yakin apabila Shameika diberi ruang untuk belajar, maka Shameika bisa melanjutkan ke sekolah terbaik di Manhattan West.

Clark sangat peduli dengan keadaan para siswanya sehingga agar semua siswa dapat melaksanakan dan lulus dan ujian nasional Clark memberikan pelajaran tambahan untuk salah satu muridnya yaitu Tayshawn. Selama ini Tayshawn dikenal sebagai anak yang sering membuat masalah dikenal.

Setting: Clark memberikan pelajaran tambahan untuk Tayshawn.

Tokoh: Ron Clark dan Tayshawn.

Adegan dimulai pada menit 01.00 .58

Ron Clark : Come on Tayshwan, you can do this.

Tayshwan : Yo, no with you all $\mathrm{u}$ on me, man!

Ron Clark : Yeah.

Tayshwan : "X" equals 3/8

Ron Clark : Yes, that's great. Just keep doing it that.

Clark memberikan pelajaran tambahan untuk Tasyshwan. Dia percaya bahwa sebenarnya Tayshawn merupakan anak yang cerdas. Akan tetapi karena Tayshawn tinggal bersama ayah tirinya yang jahat, sehingga membuat Tayshawn malas untuk belajar. Clark mencari Tayshawn karena tidak datang untuk melihat pertunjukan opera. Clark menyusul Tayshawn kerumahnya, namun tidak ada. Dia mencari Tayshawn disekitar rumahnya. Alangkah kagetnya Clark ketika menemukan Tayshawn ditempat sampah dengan badan dan muka yang penuh dengan luka.

Setting: Clark menemukan Tayshwan ditempat sampah dengan penuh luka.

Tokoh: Ron Clark dan Tayshawn.

Adegan dimulai pada menit 01.19.14

Ron Clark : I'm here.

Tayshwan : Get away, get away. I ain't worth it.

Ron Clark : No, no, no. I know you are. I saw your work. And it's beautiful. It's ok. Tayshwan : Where am I gonna go now, Mr. Clark?

Ron Clark : I'm gonna help you. I'm not going anywhere. Ok.

Tayshawn diusir oleh ayah tirinya karena membuat grafiti dikamarnya. Kemudian, Clark menemukan Tayshawan tergeletak didekat tempat sampah dengan badan yang penuh luka. Melihat hal tersebut, Clark langsung memeluk 
Tayshawn dan berjanji akan mencarikan tempat yang aman untuk tinggal. Clark membawa Tayshawn ke panti asuhan, dia yakin panti asuhan adalah tempat yang terbaik untuk Tayshawn tinggal.

Temuan ini didukung oleh Kartinawati (2014) dalam penelitiannya. Penelitian ini mendeskripsikan tentang tokoh utama yang digambarkan mempunyai integritas diri sebagai seorang pemimpin. Persamaannya dengan penelitian ini yaitu menggambarkan tokoh utama yang mempunyai integritas diri.

\section{SIMPULAN}

Dimensi dasar manusia pada tokoh utama dalam film The Ron Clark Story menunjukan tentang tiga dimensi dasar manusia yaitu: dimensi fisik, dimensi psikologis, dan dimensi sosial. Dimensi fisik pada tokoh utama Ron Clark yaitu yang berkaitan dengan kebutuhan tempat tinggal dan pelakuan fisik. Dimensi psikologis pada tokoh utama Ron Clark yang terdiri dari kecerdasan intelektual, kecerdasan emosional, dan kecerdasan spiritual. Dimensi sosial ditunjukan yang berkaitan dengan kebiasaan tolong menolong. Demikian tokoh utama Ron Clark mempunyai integritas diri karena terdapat tiga dimensi dasar manusia pada tokoh Clark.

\section{DAFTAR PUSTAKA}

Archer, A. (2017). Integrity and the value of an integrated self. Journal of Value Inquiry, 51(3), 435-454. https://doi.org/10.1007/s10790-017-9587-8

Barnard, A., Schurink, W., \& De Beer, M. (2008). A conceptual framework of integrity. SA Journal of Industrial Psychology, 34(2), 40-49. https://doi.org/10.4102/sajip.v34i2.427

Ceretti, F. C. (2015). MAIA (Movie Analysis in Action). A New Teaching Method in Media Literacy Education. Procedia - Social and Behavioral Sciences, 174(February 2015), 4053-4057. https://doi.org/10.1016/j.sbspro.2015.01.1154

Cohen, G. L., \& Sherman, D. K. (2014). The psychology of change: Selfaffirmation and social psychological intervention. Annual review of psychology, 65, 333-371.

Denzin, \& Lincoln. (2000). Handbook of Qualitative Research. London: Sage Publication Inc. 


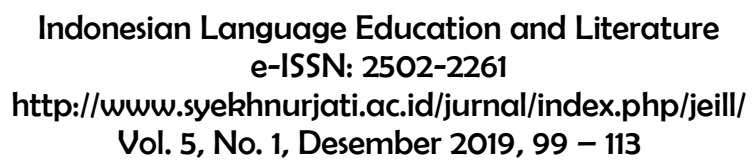

Dunn, C. P. (2009). Integrity matters. International Journal of Leadership Studies, $5(2), 102-125$.

Gea, A. A. (2014). Integritas Personal dan Kepemimpinan Etis. Humaniora, 5(2), 950-959.

Gea, A. A., Wulandari, A. P. Y., \& Babari, Y. (2005). Character Building I: Relasi dengan Diri Sendiri. Jakarta: Gramedia Pustaka Utama.

Kartinawati, E. (2014). Film dan Konstruksi Citra Politik (Analisis Wacana Politik Pencitraan dalam Film Jokowi). Komunikasi Massa Jurnal, 133.

Montifiore, A., \& Vines, D. (1999). Integrity in The Public and Private Domains. London and New York: Routledge Press.

Parker, D. W. (2013). The relationship between ego integrity and death attitudes in older adults. American Journal of Applied Psychology, 2(1), 7-15.

Sartika, E. (2014). Analisis Isi Kualitatif Pesan Moral Dalam Film Berjudul "Kita Versus Korupsi.” Ilmu Komunikasi, 2(2), 63-77.

Setiawan, A. K. (2011). Integrasi Pendidikan Karakter Dalam Pembelajaran Berbasis Interkultural. Jurnal Pendidikan Karakter, 1, 110-118.

Syaukat, R., \& Imanjaya, E. (2011). Film Sebagai Media Social Marketing: Yasmin Ahmad Berjualan Ide Multikulturalisme. Humaniora, 2(1), 634-642.

Tanis, H. (2013). Pentingnya Pendidikan Character Building dalam Membentuk Kepribadian Mahasiswa. Humaniora, 4(2), 1212-1219. 